\title{
Proposta e análise de indicadores para reorientação do serviço na promoção da saúde: um estudo de caso no Centro de Saúde Escola Germano Sinval Faria
}

\author{
Proposal and analysis of indicators for \\ the health promotion orientation service: a case \\ study in Germano Sinval Faria Health Center
}

Inês Nascimento de Carvalho Reis 1

Marcos Besserman Vianna 1

\footnotetext{
1 Centro de Saúde Escola Germano Sinval Faria, Escola Nacional de Saúde Pública, Fiocruz.

Rua Leopoldo Bulhões 1.480, Manguinhos, 21041-210, Rio de Janeiro RJ. inesreis@ensp.fiocruz.br
}

\begin{abstract}
The Training Health Center belongs to an institution which performs in different areas such as research, teaching, technology development and a service on public health. This article presents conceptual issues on health promotion, one important step of this Health Center, and evaluation points to the staff and patients cheking if this Health Center is a health promotion or not. To perform this evaluation, questionnaires in interviews are used. There are many actions towards the health promotion, but many of them are still not sustainable. The discussion and evaluation of this comparison will point to reach the Health Center goal which is to be a reference on health promotion. Some questions are based on approved indicators by the team to evaluate the health services "re-orientation" focusing in more two main ones: multi-disciplinarity and changed environment.
\end{abstract}

Key words Health promotion, Orientation service, Proposal of indicators
Resumo O Centro de Saúde Escola pertence a uma instituição de pesquisa, ensino, desenvolvimento tecnológico e prestação de serviços em saúde pública. O artigo apresenta marcos conceituais sobre promoção da saúde, um dos objetivos deste centro de saúde, e lista indicadores para serem avaliados por seus trabalhadores e usuários. Utilizaram-se questionários aplicados em entrevistas. Conclui que o Centro tem muitas ações de promoção da saúde, ainda não auto-sustentáveis, e mostra que está caminhando para ser um centro de referência em promoção da saúde. Os indicadores propostos foram aprovados para avaliar a reorientação do serviço e, ao final, sugeridos mais dois: análise da multidisciplinaridade e do ambiente construido.

Palavras-chave Promoção da saúde, Reorientação de serviço, Proposta de indicadores 


\section{Apresentação}

A Escola Nacional de Saúde Pública (ENSP), da Fundação Oswaldo Cruz (Fiocruz), vinculada ao Ministério da Saúde do Brasil, tem um departamento denominado Centro de Saúde Escola Germano Sinval Faria (CSEGSF), criado em 1967. Este Centro de Saúde Escola (CSE) tem como principais objetivos prestar assistência multidisciplinar, prioritariamente à sua vizinhança, a população moradora no Complexo de Manguinhos, no município do Rio de Janeiro; realizar atividades de educação, prevenção e promoção da saúde; desenvolver tecnologia, pesquisa e ensino na área da saúde pública.

A ENSP tem fortalecido, desde 1994, um processo de articulação entre as várias ações comunitárias voltadas para servir à população de Manguinhos. Em 1999, foi estabelecida uma parceria entre a ENSP, a Associação Canadense de Saúde Pública (CPHA) e a Associação Brasileira de Pós-Graduação em Saúde Coletiva (Abrasco), numa iniciativa de cooperação para transferência de tecnologia entre Canadá e Brasil na área da promoção da saúde, resultando em várias experiências. Dentre elas destacase a reorientação do CSE, que vem alterando sua forma de gestão e práticas, com enfoque na intersetorialidade, articulando-se com a comunidade e outras parcerias, para o enfrentamento dos problemas locais com uma visão global.

Em Reis et al. (2002) verifica-se que a principal estratégia para a reorientação dos serviços do CSE está centrada, desde 2000, na existência de um Conselho Gestor paritário entre instituição e usuários, dando direito a voto em todas as suas deliberações. Atualmente, é composto por sete usuários eleitos por participantes de grupos assistenciais do CSE, Organização Não-Governamental (ONG) e pelo Fórum Comunitário de Manguinhos; e sete membros institucionais, ou seja, a chefia do CSE, que é eleita pelos funcionários e usuários membros do Conselho Gestor, suas três Coordenações, um representante eleito pelos funcionários e dois representantes de instâncias municipais do Governo. O CSE presta assistência multidisciplinar, individual e coletiva, inerentes à atenção primária do Ministério da Saúde, contando com quinze consultórios, três salas para grupos e infra-estrutura de serviços complementares, incluindo sistema de vigilância epidemiológica com visita domiciliar. $\mathrm{O}$ atendimento à população é oferecido através da demanda organizada, que corresponde à consulta agendada, marcada em intervalos de até três horas; e através da demanda espontânea, organizada em triagem multidisciplinar. Comparado com muitos postos, o atendimento é diferenciado, voltado aos grupos por ciclos de vida, favorecendo prestar orientação a toda a demanda. Pergunta-se, semanalmente, aos usuários da Triagem, se preferem a organização do atendimento por grupos de ciclos de vida ou pela ordem de chegada, sendo unânime a aprovação pelo primeiro. Isto contribui para uma relação mais saudável entre o profissional e seu trabalho, um maior acolhimento à população, humanizando mais a equipe e a clientela. $\mathrm{O}$ enfoque passa a estar centrado no indivíduo como cidadão, com direito a saúde, e no coletivo como uma oportunidade para educação em saúde e estímulo à promoção da saúde e a cidadania.

Atualmente, muitos profissionais do próprio CSE e de outros setores o denominam de Centro Promotor de Saúde. O presente artigo definirá marcos conceituais da reorientação de serviço para promoção da saúde relacionando alguns indicadores que serão, em seguida, avaliados por profissionais de saúde e usuários do CSE segundo as ações existentes.

\section{Marcos da promoção da saúde para a reorientação de serviço}

Historicamente, como apresentado por Minayo e Miranda (2002) os condicionantes do processo de adoecimento numa perspectiva social já eram destacados por Engels, antigo colaborador de Marx, que atribuía o sofrimento dos operários a doenças infecciosas, como a tuberculose, ou ainda a outras causadas por toxinas, toxinas ambientais e alcoolismo. Em 1840, constatou-se, na Inglaterra, que os fatores que mais contribuíam para uma melhor qualidade de vida da população eram o desenvolvimento econômico e uma melhor qualidade nutricional. Virchow, num inverno de 1847, foi convidado a estudar uma epidemia do tifo e recomendou que a população vitimada necessitava, entre outras intervenções médicas, de completa e ilimitada democracia, educação, liberdade e prosperidade.

Em 1946, Singerist utiliza pela primeira vez o termo promoção da saúde, quando ele tenta reordenar o sentido da Medicina em quatro funções: a promoção da saúde, a prevenção das enfermidades, a cura e a reabilitação. Mas, con- 
sidera-se o primeiro grande marco conceitual da promoção da saúde o Informe Lalonde. Datado de 1974, estabeleceu quatro dimensões do processo saúde-enfermidade-cuidado, sendo uma delas a organização do sistema de atenção à saúde. Esta consiste na quantidade, qualidade, ordem, índole e relações entre as pessoas e os recursos de provisão da atenção à saúde.

Naquela ocasião, a Organização Mundial da Saúde (OMS) realizou missões à China para conhecer o sistema de saúde implantado a partir de 1965, na zona rural. Destacaram-se as ações de prevenção voltadas à autoconfiança popular e valorização de tratamentos à base de ervas medicinais (Buss, 2000).

A Declaração de Alma-Ata, de 1978, teve como base Saúde para Todos no Ano 2000, reafirmando a justiça social e a eqüidade como pré-requisitos para a saúde. Esta foi aprofundada no segundo grande marco, a Carta de Ottawa, datada de 1986, que ampliou a concepção de promoção da saúde, incorporando a importância e o impacto dos aspectos socioeconômico-político-psicocultural aos determinantes de saúde. Conceituou a reorientação dos serviços de saúde a partir de uma visão ampla que deve ser modificada gradativamente com a participação dos indivíduos e sociedade na criação de um novo sistema de saúde, a partir de uma definição e conquista conjunta, sempre considerando os serviços clínicos e de urgência. Devese, portanto, valorizar a capacitação dos profissionais para mudanças de atitudes, a intersetorialidade, a comunicação e a pesquisa.

A Declaração de Adelaide, de 1988, ao reforçar a importância de políticas públicas saudáveis, aponta para a necessidade de uma abordagem integrada de reforma e desenvolvimento socioeconômico e de saúde. Identificou quatro áreas prioritárias: apoio à saúde, informação e participação da mulher; políticas, ações e informações de valorização à alimentação e nutrição adequadas; combate ao tabagismo e alcoolismo através de fortes políticas e ações; e criação de ambientes saudáveis e auto-sustentáveis. Isto é reforçado na Declaração de Sunsdvall, de 1991, que responsabiliza a todos pela criação de ambientes favoráveis e promotores de saúde, frisando a educação neste contexto. A Conferência de Jacarta, a primeira realizada em país em desenvolvimento, fez uma avaliação positiva da Carta de Ottawa, estabelecendo cinco prioridades para a promoção da saúde, com destaque para os dois últimos itens: promover responsabilidade social para com a saúde; au- mentar os investimentos para fomentar a saúde; consolidar e expandir parcerias em prol da saúde; aumentar a capacidade comunitária; e dar direito de voz ao indivíduo, o empowerment.

A dimensão da promoção da saúde expressa nos últimos encontros internacionais direcionados para o redimensionamento do papel da saúde pública culminaram na Rede de Megapaíses para Promoção da Saúde, de 1998. Isto favorece os países em desenvolvimento, repercutindo em políticas e ações para saúde, sendo um exemplo o já citado Projeto de Transferência de Tecnologia entre Brasil e Canadá. Outro exemplo é a estratégia criada pela Organização Pan-Americana de Saúde (OPAS) e a OMS para estimular a reorientação do sistema de saúde com vistas à promoção da saúde, apoiando iniciativas que incorporem entornos saudáveis e viabilidade de desenvolvimento social, incluindo a avaliação da qualidade, resolutividade e humanização da atenção, tendo como objetivo central a contribuição para melhoria da qualidade de vida (Malo, 2002; OPAS, 2004).

O Brasil tem sua legislação coerente com essa proposta, como citado em sua Constituição, de 1988, no artigo 196, a saúde é direito de todos e dever do Estado, garantindo mediante políticas sociais e econômicas que visem à redução do risco de doença e de outros agravos e ao acesso universal e igualitário às ações de serviço para a sua promoção, proteção e recuperação. E, ainda, na regulamentação infraconstitucional, a lei 8.080 , de 1990 , nos artigos $2^{\circ}$ e $3^{\circ}$, diz que as políticas sociais e econômicas protetoras da saúde individual e coletiva são as que atuam diretamente sobre fatores determinantes e condicionantes da saúde, como: alimentação, moradia, saneamento básico, meio ambiente, trabalho, renda, educação, transporte, lazer e acesso aos bens de serviços essenciais. O dever de Estado de prover as condições indispensáveis ao exercício do direito do cidadão à saúde não exclui o dever das pessoas, da família, das empresas e da sociedade, destacando a questão da autonomia e da responsabilidade social. Aspectos estes já contemplados na criação do Sistema Único de Saúde (SUS).

Em 2002, o I Fórum Mundial de Saúde convida a todos a assumirem suas responsabilidades na construção de sociedades justas e eqüitativas, e com ações sustentadas (Alames et al., 2002). A 12a Conferência Nacional de Saúde do Brasil (2004), em 2003, aborda esta ques- 
tão e um dos caminhos está em dois de seus eixos temáticos intitulados a intersetorialidade das ações de saúde e a organização da atenção à saúde, que têm o apoio do governo. Este reconhece que o primeiro é fundamental para a obtenção da promoção da saúde, e o segundo deve também incorporar tecnologias e a metodologia de educação e promoção de hábitos saudáveis, entre outros para garantir os novos rumos da reforma sanitária brasileira.

Parte-se da premissa que, para o sucesso do trabalho a partir da promoção da saúde, o profissional de saúde deve estar aberto ao diálogo, como definido por Paulo Freire (2000), um dos norteadores das instituições de promoção da saúde no Canadá. Para estimular o empowerment, o profissional de saúde deve ser um mediador dos recursos existentes, através de um atendimento humanizado, sendo a capacitação fundamental (Vasconcelos, 1988; Stotz \& Valla, 2001). Isto torna-se ainda mais importante quando se assume a abrangência do termo promoção de saúde e a necessidade de definição de indicadores de avaliação diferentes dos referenciais tradicionalmente utilizados, devendo suscitar debates entre os profissionais envolvidos em mudança da qualidade de vida, com ações intersetoriais, com mobilização e participação comunitária. A importância desta temática é amplamente apresentada em Zancan et al. (2002), pois acredita-se que este é o caminho da promoção da saúde para o alcance do desenvolvimento local integrado e sustentável (DLIS). Estas questões estão latentes no CSE. A seguir, destacam-se reflexões dos autores com profissionais/gestores e usuários do CSE, sobre indicadores de reorientação do serviço para promoção da saúde.

\section{Metodologia}

A metodologia adotada é inspirada no que Minayo (1998) chama de ciclo de pesquisa, ou seja, é um processo de trabalho que começa com a fase exploratória, na qual preliminarmente se interroga sobre o objeto, os pressupostos, as teorias e metodologia pertinentes; o trabalho de campo que "consiste no recorte empírico da construção teórica elaborada"; e o tratamento do material recolhido no campo, que produz um confronto entre a abordagem teórica e o que a investigação de campo traz de contribuição singular. A experimentação de campo também favorece a transformação dos "papéis dos pes- quisadores e dos sujeitos que participam da experiência bem como suas relações recíprocas" (Bruyne et al., 1982).

Os autores estabeleceram alguns indicadores para avaliar a afirmativa de que o CSE é um centro promotor de saúde, com base nos marcos conceituais apresentados anteriormente, conforme listado a seguir. Entretanto, ressaltam que este é um primeiro ensaio em um estudo de caso, reconhecendo a importância de ser um debate necessário por abranger a qualidade de vida do cidadão, entendida como desenvolvimento integral do ser humano, sendo um desafio que precisa ser enfrentado pelos serviços de saúde, além da necessidade de incorporação da vida cotidiana nas ciências sociais (Minayo et al., 2000; Fleck, 2000; Canesqui, 1995).

\section{Lista de indicadores utilizados para avaliar o Centro de Saúde Escola Germano Sinval Faria como promotor de saúde}

- controle social

- articulação intersetorial

- preocupação com a justiça social e eqüidade

- participação para o desenvolvimento social e econômico saudável e auto-sustentável

- participação para o desenvolvimento ambiental saudável e auto-sustentável

- organização da demanda e protocolos por ciclo de vida

- contribuição para o controle de enfermidades transmissíveis

- contribuição para o controle de enfermidades não transmissíveis

- redução ao tabagismo e outras dependências químicas

- contribuição para mudanças de estilo de vida

- respeito às necessidades individuais e peculiaridades culturais

- desenvolvimento tecnológico

- pesquisa

- capacitação profissional para mudança de atitudes

Para o levantamento dos dados foi elaborado um questionário semi-estruturado que serviu de base para entrevistar pelo menos um trabalhador de cada programa/ação de promoção da saúde, profissionais que trabalham em ações basicamente biomédicas, membros do 
Conselho Gestor que pertenciam e não pertenciam ao quadro funcional do CSE e um profissional de uma Organização Não-Governamental (ONG) que faz parceria com o CSE. Perguntou-se à pessoa o que era promoção da saúde; a concordância ou não com o CSE ser nomeado centro promotor de saúde e qual a razão da resposta; e, ainda, se apresentou cada um dos indicadores listados acima para responderem se o CSE cumpria ou não o quesito, e quais as ações que justificavam os casos de respostas positivas. As entrevistas foram individuais, garantida a confidencialidade e com duração média de uma hora, chegando até a três horas no máximo.

Foram entrevistadas dezoito pessoas relacionadas diretamente a ações do CSE, inclusive Conselho Gestor, correspondendo a $21 \%$ dos trabalhadores do CSE e 15\% de seu colégio eleitoral (dezembro de 2003). Todos os grupos de trabalho com práticas priorizadas em promoção da ação foram contemplados (Desenvolvimento Local Integrado e Sustentável/DLIS/Manguinhos, Estratégia de Saúde da Família/ESF, Núcleo de DST/AIDS, Núcleo de Práticas Naturais em Saúde/NuPNS, Centro Colaborador de Alimentação e Nutrição/CECAN, Programa de Atenção ao Idoso/PASI, Núcleo de Ações e Estudos de Comunicação em Promoção da Saúde/NAECOS, Núcleo de Estudos de Diretos Humanos e Saúde/NEDH), e também os Módulos de Atendimento (Criança, Mulher e Adulto) e membros do Conselho Gestor. É interessante ressaltar que sete profissionais têm mais de uma função, conforme apresentado no quadro 1. Foram entrevistados dois usuários que são membros do Conselho Gestor. Cinco entrevistados (27\%) são moradores de Manguinhos, sendo que quatro são funcionários também. Somente três entrevistados estão no CSE há menos de dois anos. O

\section{Quadro 1}

Ações dos entrevistados com o Centro de Saúde Escola Germano Sinval Faria.

\begin{tabular}{lc}
\hline Relação & No \\
\hline Promoção da saúde & 5 \\
Assistência biomédica & 3 \\
Usuário no Conselho Gestor e parceria institucional & 3 \\
Promoção da saúde e assistência biomédica & 5 \\
Promoção da saúde, assistência biomédica e & 2 \\
Conselho Gestor & \\
\hline
\end{tabular}

restante está há mais de quatro anos, o que poderia permitir um conhecimento geral do CSE e das análises a serem feitas.

A técnica utilizada possibilitou uma aproximação entre pesquisador e entrevistado, permitiu que as respostas não fossem induzidas e avaliassem também a utilidade dos indicadores propostos. Isto se fez necessário considerandose Lévi-Strauss (1975): a ciência onde o observador é da mesma natureza que o objeto, o observador é uma parte de sua observação. Isto contribuiu para se concluir que será enriquecedor ampliar o estudo com uma metodologia de pesquisa-ação que estimule a integração e participação de todo o CSE. A pertinência da temática é notória também quando destaca a missão institucional diante do conceito de qualidade de vida e de promoção da saúde e a importância de um aprofundamento em sua medição, como aponta Minayo, Hartz e Buss (2000). A avaliação é um campo de conhecimentos aplicados e uma ferramenta estratégica para o planejamento e a gestão de programas e projetos, como concluído no relatório da I Oficina de pesquisa Avaliativa em Promoção da Saúde e Desenvolvimento Comunitário, no V Congresso Brasileiro de Epidemiologia (Hartz et al., 2002).

\section{Análise dos resultados}

Constatou-se no conjunto das entrevistas a necessidade de um sistema de informação que permita uma socialização maior de todas as práticas dos últimos anos. Percebeu-se que a maioria sabia da existência de muitas ações, mas sem um conhecimento mais aprofundado, como demonstraram querer, apontando que caberá um estudo sobre as razões da queixa relativa à falta de informação. Esta queixa também está presente nas assembléias que têm grande participação, embora muitos assumam que não fazem uso dos mecanismos existentes, como o comparecimento no Conselho Gestor e nos Centros de Estudos, que são reuniões abertas, e leitura dos painéis internos, o que fica evidente nas análises dos indicadores, a seguir.

\section{Definição de promoção da saúde para os entrevistados}

Houve uma coincidência nas respostas possibilitando que fossem agrupadas em cinco, como apresentado no quadro 2. A maioria dos 
Quadro 2

Agrupamento de definições dos entrevistados sobre promoção da saúde.

\begin{tabular}{llc}
\hline Grupo & Definição & № \\
\hline $\begin{array}{l}\text { Responsabilidade } \\
\text { institucional/profissional }\end{array}$ & Favorecer práticas saudáveis, em um sentido amplo & 6 \\
\cline { 2 - 3 } & Construir junto com o usuário/comunidade & 5 \\
\cline { 2 - 3 } & Prevenir doença e educação em saúde & 4 \\
\cline { 2 - 3 } & Ter mais especialidade médica & 1 \\
\hline Responsabilidade individual & Ter práticas saudáveis, viver bem, feliz & 6 \\
\hline
\end{tabular}

entrevistados correlacionou promoção da saúde a responsabilidades institucionais/profissionais $(78 \%)$ e o restante a iniciativas individuais. Alerta-se para o fato de que quatro pessoas aparecem em mais de um agrupamento, mas apresentando uma lógica complementar e não contraditória.

O CSE era voltado à atenção primária, logo, encontrar a definição de que devemos caminhar com o outro, trabalhar junto com a comunidade, através da troca de experiência, não adiantando só informar, é construir juntos, a partir dos saberes de cada um (sic), demonstra a mudança dos conceitos que ocorrem historicamente a partir das práticas estabelecidas. Como apresentado no quadro 2, setenta e dois por cento dos entrevistados deram definições próximas às expostas no marco conceitual. Entretanto, o destaque foram as relações institucionais, mas em outra pesquisa em andamento no CSE, sob nossa assessoria, 79\% dos trabalhadores apresentaram conceitos mais próximos ao autocuidado, ainda que dentro dos pressupostos da promoção da saúde (Penna, 2004).

Foi de um usuário a única definição voltada para o atendimento à doença exclusivamente necessidade de ter mais especialidades médicas. O outro usuário, pertencente à terceira idade, participa ativamente do dia-a-dia do CSE, contribuindo para que dissesse: "é viver de bem com a vida", o que foi encontrado em $27 \%$ das análises. Percentual similar (29\%) aconteceu quando, sob nossa orientação, Penna (2004) entrevistou 190 usuários do CSE. Este conceito foi destacado por $46 \%$ dos visitantes entrevistados no evento Fiocruz pra Você, que acontece anualmente durante a Campanha Nacional de
Vacinação na Fiocruz (Reis et al., 2003), apontando a consciência de um conceito mais voltado para a saúde do que para a doença.

\section{Opinião sobre o CSE ser um centro promotor de saúde}

O reconhecimento sobre a reorientação do centro de saúde para a promoção da saúde é notória, seja no resultado concordante de $22 \%$, seja no caso de $61 \%$ que afirmam que "está cada vez mais caminhando nesta estrada” (sic). A justificativa está em achar que "todos os profissionais e estagiários estão trabalhando para isto" (sic), conhecendo as necessidades de seus pacientes, procurando fazer um atendimento humanizado, evitando medicalizar a clientela e trabalhando mais com a população, sendo apresentada a opinião de que funciona melhor do que outras instituições.

Foi citado que a falta de investimento institucional e de capacitação dos recursos humanos tem sido um limitador para o CSE ser mais prontamente nomeado promotor de saúde (11\%). Outro fato apontado por um entrevistado foi a sobrecarga de consultas e atribuições assumidas por profissionais comprometidos com o trabalho e a população.

\section{Controle social}

Todos reconheceram que o CSE tem uma gestão participativa, sendo que $78 \%$ das pessoas citaram como exemplo o Conselho Gestor. Mas, 28\% acham que a participação do usuário precisa melhorar. O próprio usuário aponta que nem sempre entende o que é dito e "quan- 
do vou para reunião já está tudo decidido, a gente só faz figuração" (sic). Por outro lado, o mesmo usuário e um trabalhador do PASI reconhecem sua utilidade quando citam que está sendo conseguido geriatra para o CSE por existir usuários do Programa no Conselho Gestor. Outro exemplo de gestão participativa foi a interferência da opinião dos usuários para permanência de um dentista no ESF. Apesar de a gestão participativa ser um processo em amadurecimento, acredita-se na seriedade da gestão em buscar alternativas que incluam cada vez mais o usuário e representantes da sociedade nas tomadas de decisão do CSE, sendo observada a valorização pelo conjunto dos servidores nesta prática. Como exemplo, ainda foram citados os grupos que têm uma gestão participativa direta do usuário, como Terrapia e Núcleo DST/AIDS e indireta como o NAECOS, com a pesquisa de opinião do usuário.

\section{Articulação intersetorial}

A intersetorialidade também foi reconhecida pela unanimidade dos entrevistados. Foi notória esta nova estratégia do CSE, demonstrada pelas respostas acompanhadas de vibração. Foram listadas várias parcerias. Metade mencionou a aproximação entre a academia da ENSP e o CSE, e também da própria Fiocruz (33\%). Mas, surpreendente foi a quantidade de parcerias externas enumeradas: metade com outras instituições governamentais e empresariais, além de ONGs (44\%); e com escolas e creches locais (22\%).

A articulação que mais estimula o $\mathrm{em}$ powerment é aquela em que a população está presente, o que está representado na participação de ações com Associações de Moradores e no Fórum Local. Este é um processo que está no início e ainda depende da motivação de alguns poucos para que seja auto-sustentável, para que independa da política, da economia, que transcenda as intempéries para ser um modo de vida institucional.

\section{Preocupação com a justiça social e eqüidade}

A maioria dos entrevistados (83\%) acha que o CSE está preocupado com a justiça social e eqüidade, citando como ações: práticas realizadas pelo Núcleo de DST/AIDS, notadamente o Bazar da Solidariedade (44\%); atendimento jurídico feito semanalmente no CSE em parce- ria com uma ONG local (39\%); abordagens realizadas pelas equipes da ESF (33\%); promoção de curso de alfabetização para jovens e adultos em parceria com o Ministério da Educação $(22 \%)$.

Foram citadas em igual proporção ( $11 \%$ cada): triagem, por atender a todos sem precisar acordar de madrugada, tendo como único limite o horário; o PASI, pela metodologia e resultados observados; o Conselho Gestor e o DLIS, por estimularem a envolvimento da população nas priorizações e soluções dos problemas.

Enumeraram-se 13 ações somente uma vez, mas que podem ser divididas em dois grupos expressivos, chamados de extramuros, que ocorrem a partir de ações externas ao CSE (atendimento de ONG contra violência à mulher; retirada de documentação obrigatória por lei; inclusão escolar e no mercado de trabalho; estimulo à criação de coletivo de mulheres) e de intramuros (divulgação sobre os atendimentos do CSE, processo de acreditação em atenção básica, orientação à demanda espontânea sem limite de horário, trabalhos sobre segurança alimentar, alimento vivo, combate à dependência química, atendimentos de serviço social e de grupos não especificados).

\section{Participação para o desenvolvimento social e econômico saudável e auto-sustentável}

Quase a unanimidade dos entrevistados, exceto um, concorda que o CSE estimula o desenvolvimento social e econômico saudável e auto-sustentável. Foram citadas mais ações na área social (63\%), sendo reconhecido o estímulo à inclusão social através de trabalhos desenvolvidos pelo ESF; PASI; alfabetização de jovens e adultos; atividades culturais e esportivas no Projeto Casa Viva/DLIS, notadamente a capoeira; criação do coletivo de mulheres; além de orientações sobre saúde partilhadas com diversos profissionais, inclusive durante seções de cabeleireiro que aconteceram na sala de espera do CSE. Os exemplos foram relacionados à justiça social e eqüidade também. Fortalecer as mulheres e os idosos, diminuir a violência, a discriminação pela ignorância, a ociosidade, almejando uma sociedade mais justa, aparece nos sentimentos durante as falas. Um exemplo: "aqui há muito boa vontade, se faz muito considerando que temos pouco recurso" (sic).

O destaque nas ações relacionadas ao desenvolvimento econômico foi a Oficina Artesa- 
nal, associada ao Bazar da Solidariedade (44\%), que promove capacitação de moradores de Manguinhos e geração de renda. A orientação sobre o aproveitamento integral dos alimentos e sobre a compra mais barata conforme as safras foram mencionados (Cecan e NuPNS), demonstrando uma sensibilidade pela "economia indireta". Outros exemplos foram: o fornecimento de cesta básica de alimentação, inserida no Programa Fome Zero; iniciativas individuais de auxílio à obtenção de emprego; e permissão, pela chefia, para que moradores vendam em feiras promovidas pelo CSE e parceiros. Ninguém avaliou a inserção do CSE no desenvolvimento local integral e auto-sustentável, possivelmente por ainda ser mais um conceito com ações pontuais sem ter difundido práticas cristalizadas e de impacto, por ser o DLIS um processo e não um projeto, já que todas as ações da área social identificadas fazem parte do processo de DLIS.

\section{Participação para o desenvolvimento ambiental saudável e auto-sustentável}

A questão do desenvolvimento ambiental não é amplamente percebida pela maioria dos entrevistados, considerando não terem identificado ações que trabalhassem com a temática (61\%). Do universo de entrevistados, 28\% apontaram o Projeto Terrapia como tendo preocupação com o meio ambiente, correspondendo a $71 \%$ dos que responderam sim ao cumprimento deste indicador. Cabe esclarecer que este Projeto pertence ao NUPNS e estimula a prática de cuidado consigo, com a alimentação e com o meio ambiente a partir da produção e consumo do alimento vivo em horta experimental.

Foram citados, também, trabalhos ligados à participação comunitária no CSE (ESF e DLIS); e parceria deste com a Universidade Aberta e o Laboratório Territorial, também pertencentes a ENSP, que tem várias ações relacionadas à educação ambiental.

Entretanto, a auto-sustentabilidade ainda não é conseguida nas práticas do CSE, o que é confirmado por $43 \%$ dos que apontaram estas ações. Reconheceu-se que é uma caminhada importante e em desenvolvimento, cabendo valorizar a intersetorialidade a partir do reforço de políticas e ações institucionais, disponibilizando recursos para isto.

Nota-se que o enfoque dado ao termo sustentável foi aplicado no sentido estrito de con- tinuidade do processo, não abrangendo uma mudança cultural ou mesmo de aproximação das instâncias de decisão.

\section{Organização da demanda e protocolos por ciclo de vida}

Grande parte dos entrevistados (72\%) acha que o CSE organiza sua demanda por ciclo de vida. Metade apontou a triagem como exemplo, já que as pessoas não são atendidas individualmente, salvo se assim desejarem, pois são chamadas pelo nome para comparecerem em uma sala onde são orientadas em grupo conforme a faixa etária. Outro exemplo é que os atendimentos agendados são direcionados por módulos distribuídos conforme o ciclo de vida, o que facilita a organização.

A mesma proporção (72\%) não conseguiu, todavia, citar ações que apontassem que os atendimentos são organizados em protocolos por ciclo de vida. Reconhece-se que o PASI favorece $\mathrm{o}$ atendimento à terceira idade, mas se destaca a inexistência de atendimento direcionado ao adolescente. O CSE passa por um processo de acreditação que poderá estimular este trabalho. Ressalta-se que não há procedimentos de acreditação específicos à atenção primária e menos ainda voltados à promoção da saúde, sendo o CSE o primeiro nessa ótica, pelo que foi apontado pela equipe do Consórcio Brasileiro de Acreditação (CBA), que tem prestado assessoria aos serviços da Fiocruz com a Joint Commission International.

\section{Contribuição para o controle de enfermidades transmissíveis}

Todos os entrevistados concordam que o CSE contribui para o controle de enfermidades transmissíveis sendo citadas ações das equipes do Núcleo de DST/AIDS, ESF e de Tuberculose: visita domiciliar de acompanhamento ao paciente e familiar, grupos específicos, distribuição de cartilhas e medicamentos e realização de palestras. Entre os entrevistados, 33\% frisaram, também, que nas consultas são feitas orientações sobre o assunto e no caso da DST/ AIDS há diferentes estratégias na distribuição de preservativos (participação em diversos tipos de campanhas, não só relacionadas ao tema, Camelô Educativo, e grupos com atividades na comunidade).

Um entrevistado acrescentou a seriedade e a criatividade na busca das soluções para apoi- 
ar os portadores de HIV, mas citou a necessidade de uma intervenção ainda maior, desde o início da educação fundamental, sugerindo um trabalho mais próximo ao Programa Escolas Promotoras de Saúde. Cabe observar que este Programa é uma parceria do Ministério da Saúde com o da Educação. A ENSP tem um grupo que trabalha em escolas locais com participação do CSE, sendo pertinente o incremento nesta área.

\section{Contribuição para o controle de enfermidades não transmissíveis}

Muitos (61\%) identificam que o CSE tem contribuído para o controle de enfermidades não transmissíveis, citando: orientação nas consultas, atendimentos de grupos específicos, distribuição de medicamentos e organização da demanda do adulto por doenças crônicas. Mas, somente 33\% citaram ações relacionadas basicamente à promoção da saúde, ou seja, ter aumentado o número de encaminhamentos aos grupos não convencionais e de parcerias com as escolas e a comunidade/ESF, além de palestras. Foi destacado que os trabalhos assistenciais ainda são mais voltados a medicar do que a orientar, tendo sido exemplificado o término das atividades que eram realizadas na sala de espera.

\section{Redução ao tabagismo \\ e outras dependências químicas}

A maioria (78\%) não identifica ações em que o CSE esteja contribuindo para a redução do tabagismo. Somente $22 \%$ mencionaram que o CSE é uma Unidade Livre do Tabaco, sendo que alguns citaram que ainda há trabalhadores que fumam dentro de CSE, apesar de minoria. Somente um apontou que servidores pararam de fumar depois desta denominação. Um citou que o Núcleo de Dependência Química $(\mathrm{Nu}-$ deq) não está capacitado para este trabalho, estando para outras dependências, como demonstrado a seguir. $\mathrm{O}$ fato de haver um tratamento para outros dependentes pode ter interferido no resultado, já que o mesmo não ocorre com o tabagismo. De qualquer maneira, isto demonstra que para os entrevistados não causou impacto o fato de o CSE ser uma Unidade Livre do Tabaco. Para os autores, entretanto, acredita-se que já é um grande ganho não se fumar mais no CSE, pois antes profissionais fumavam em ambientes fechados, até mesmo du- rante o atendimento; muitos usuários fumavam na sala de espera ao lado dos que não fumavam, apesar de se reconhecer que urge um tratamento para desintoxicação de fumantes.

O resultado já é o contrário quanto à redução de outras dependências químicas, já que $83 \%$ afirmam que o CSE contribui, sendo citado o Nudeq (67\%) e a inclusão de agente de saúde em alcoolismo no ESF (32\%). Foi experiência pioneira, além da inclusão, por um entrevistado, das orientações nas consultas. Entretanto, como citou um profissional, o Nudeq fazia um atendimento em regime de semi-internato, o que não é comum e teve que parar... Dois profissionais destacaram que o trabalho desenvolvido não segue a linha da promoção da saúde. Interessante é que nenhum profissional, nem os mais radicais quanto a práticas promotoras de saúde, citaram a necessidade de ações relacionadas à dependência química medicamentosa.

\section{Contribuição para mudanças de estilo de vida}

A quase totalidade dos entrevistados (89\%) destaca que o CSE contribui para mudanças de estilo de vida de seus usuários. O PASI foi o mais citado (33\%), sendo exemplar pela mudança que o CSE passa quando o grande número de cidadãos da terceira idade transita animadamente nos dias de grupo. Em igual proporção (22\%) mencionaram: nutrição, alimento vivo/Terrapia, atividade corporal e Camelô Educativo/DST/AIDS. Foram contribuições para mudança de estilo as orientações recebidas durante as consultas; os atendimentos do $\mathrm{Nu}$ deq e jurídico; os atendimentos em grupo, tanto da assistência biomédica quanto da promoção da saúde; e as ações voltadas para a alfabetização (17\% cada). Destacaram-se, em menor proporção ( $5 \%$ cada), outras ações relacionadas à parceria com a comunidade (melhoria nas condições de moradia e de rede de esgoto) e ao atendimento (distribuição de medicamento para DST/AIDS e de cesta básica e atendimento a tuberculosos). Interessante foi o depoimento de um profissional sobre sua mudança pessoal, combatendo o tabagismo, buscando uma alimentação e uma postura de vida mais saudáveis. As entrevistas confirmaram um sentimento que vem sendo crescente: trabalhar com o enfoque de saúde contagia os profissionais a ponto de estes atingirem não só sua clientela, mas também outros colegas de trabalho. 


\section{Respeito às necessidades individuais e peculiaridades culturais dos usuários}

O profissional do CSE convive diariamente com os moradores de Manguinhos e isto contribui para $83 \%$ identificarem inúmeras ações de respeito ao usuário e as suas peculiaridades culturais. As necessidades individuais estão expressas na credibilidade de que há um diálogo entre profissional e usuário (28\%), citando: procuramos usar a linguagem do paciente e conhecer a sua realidade. A gente conhece os pacientes pelo nome (sic). Esta relação profissional-usuário foi considerada boa por $71 \%$ dos usuários entrevistados em uma pesquisa de opinião interna (Reis et al, 2003). Foram destacadas ainda algumas ações que não têm centro de saúde que tenha e são fáceis de fazer, é só ter boa vontade (sic): água no bebedouro; banheiro limpo; agendamento sem fila e com espera de no máximo dois meses; encaminhamentos externos agendados por telefone; farmácia organizada por protocolo e fornecendo medicamento para cadastrados que estão em presídio; e grupos de apoio. A existência de um Fale Conosco e de atendimento jurídico também foram reconhecidos como ações de respeito à necessidade do indivíduo (22\%). Entretanto, foi conversado sobre a diferença entre respeito e cumprimento à necessidade do indivíduo. Escutar não significa obrigatoriamente atender às demandas, o que foi notado por $17 \%$ dos entrevistados que acharam que as necessidades não são respeitadas.

Quanto ao respeito às peculiaridades culturais dos usuários, houve naturalmente um agrupamento:

- metade mencionou sobre os atendimentos que são feitos a qualquer um igualmente, $o$ que chega de mendigo é igual ao que está bem vestido (sic); ainda foi citado por médicos que não se quer saber a religião de ninguém e se parte dos hábitos alimentares para falar de mudanças neste assunto, assim como no caso do uso de preservativo;

- $40 \%$ citaram a organização de eventos contando com a participação do usuário, seja em apresentações de dança, coral, capoeira e uso da televisão no canal que escolhem, mesmo que não seja da preferência do CSE; e

- $10 \%$ mencionaram a valorização da autoestima, seja através da alfabetização, seja através do estímulo à produção de artesanatos, pois opinamos sobre os produtos, mas estes são confeccionados como querem, independente do que sugerimos. (sic).
Acredita-se que aqui também está um retrato das aproximações e articulações que começam a existir entre CSE e comunidade. Um exemplo citado por um entrevistado e que teve repercussão institucional foi a colocação de correntes nos setores de atendimento para facilitar a organização das atividades de enfermagem. Estas pararam de ser usadas após queixas não só dos usuários no Fale Conosco, mas apresentadas por profissionais e usuários no diálogo direto com a gestão.

\section{Comunicação para promoção da saúde e direito dos usuários}

A quase totalidade dos entrevistados acha que há comunicação para promoção da saúde e direito dos usuários. Notou-se que as ações citadas foram diferentes para cada tipo de objetivo. Para promoção da saúde listaram a existência de cartazes e folhetos informativos (44\%); participação em eventos populares (27\%); ações de grupos específicos, incluindo práticas não convencionais no CSE (ESF, DST, NuPNS e NAECOS) - $27 \%$; e parceria com ONG para elaboração de apresentações audiovisuais (21\%).

Os mecanismos de comunicação sobre o direito dos usuários foram centradas em ações de três grupos: NAECOS ( $56 \%$ citam a divulgação sobre as rotinas dos atendimentos e do que existe no CSE a pesquisa de opinião do usuário, a existência de crachá para os trabalhadores e a existência do serviço Fale Conosco, onde se escutam e se encaminham as observações dos usuários); a prestação de atendimento jurídico de ONG no CSE (39\%); e a existência do NEDH (11\%). Foi citada, também, a maneira como a organização da demanda espontânea acontece. Interessante ressaltar que nenhum entrevistado correlacionou a temática como importante para o aumento da capacidade de empowerment.

\section{Desenvolvimento tecnológico e pesquisa}

A maioria teve dificuldade em identificar ações de desenvolvimento tecnológico e pesquisa, inclusive alguns dos 33\% que avaliaram positivamente. Em relação ao desenvolvimento tecnológico, cada um citou um exemplo: terapias ocupacionais da dança sênior e Oficina Artesanal; gestão participativa através do Conselho Gestor e DLIS; e melhoria de paladar de 
minerais para uso medicinal; trabalhos de divulgação do NAECOS e do Cecan, o Curso de Especialização para Gerentes de Unidades Básicas de Saúde (Gerus) e Serviço de Documentação e Informação em Saúde (Sedis), estes dois últimos voltados a instituições.

$\mathrm{Na}$ área da pesquisa prevaleceram os trabalhos desenvolvidos por grupos relacionados à promoção da saúde (22\%), sendo citado que as iniciativas costumam ser individuais ou de profissionais que vêm de fora do CSE. Houve igual proporção de entrevistados (11\%) que citaram posicionamentos contraditórios sobre o apoio de apresentação de trabalhos em eventos científicos. Isto reflete a característica histórica da falta de política estruturada e de ações do CSE neste setor, agravada pela pouca divulgação dos trabalhos desenvolvidos, o que também foi citado. Acredita-se que estes fatos também interferiram no resultado referente ao desenvolvimento tecnológico, que tem relação direta com a área de pesquisa.

\section{Capacitação profissional para mudança de atitudes}

Um indicador sobre as políticas de desenvolvimento institucional é a capacitação de seus recursos humanos. Um reflexo do resultado do item anterior pode estar em $72 \%$ dos entrevistados não terem identificado ações sobre capacitação. Estas estão restritas a iniciativas individuais, exceto no caso dos cursos sobre biossegurança e busca de excelência no atendimento, este último indicado pelo NAECOS.

As assembléias também apontam para importância de políticas e ações direcionadas ao desenvolvimento profissional/pessoal, o que já começa a aparecer no processo eleitoral, como foi citado por um entrevistado. A educação permanente é fundamental para qualidade e eficiência do desenvolvimento institucional para garantir sustentabilidade do processo de reorientação do serviço.

\section{Avaliação dos entrevistados sobre os indicadores}

Foi perguntado aos entrevistados se concordavam com os indicadores; somente um entrevistado citou não concordar com o referente ao respeito às peculiaridades culturais, alegando que o Brasil é uma miscelânea de culturase todas as nossas ações estão comprometidas com isso (sic).
Quanto à inclusão de indicadores, 56\% sugeriram alguns acréscimos: quantificação do aumento da participação de trabalhadores, da multidisciplinaridade e da comunidade; análise de impacto epidemiológico das ações caracterizadas como sendo de promoção da saúde.

Os autores concordam com os posicionamentos e caberá um estudo mais aprofundado e participativo para respaldar a criação de indicadores que quantifiquem impactos epidemiológicos e não epidemiológicos, das ações consideradas de promoção à saúde, como sugerido. Há necessidade de desenvolver protocolos baseados em evidências de ações de promoção da saúde e um monitoramento contínuo, como também definido pelo Ministério da Saúde canadense: avaliação de programa é a coleta de dados, análise e relato sistêmicos de informação a respeito de um programa no intuito de ajudar no processo de tomada de decisões (The Health Communication Unit, 2001).

\section{Conclusão}

O marco teórico apresentado sobre a promoção da saúde é utilizado como estímulo para permanência, aprimoramento e criação de ações que ampliam as responsabilidades do setor saúde. Os indicadores utilizados para avaliar se o Centro de Saúde Escola (CSE) é um centro promotor de saúde ou não foi aprovado pelos profissionais do CSE e usuários do Conselho Gestor entrevistados.

Foi destacado que o CSE está caminhando para ser um centro promotor de saúde, diferenciando-se dos núcleos de atenção primária, mesmo os de saúde da família, que não incorporam de forma tão radical nem a intersetorialidade nem a oferta de práticas diversas (Terrapia, Oficina Artesanal, Bazar da Solidariedade, Camelô Educativo, dança sênior, coral, atividades corporais, meditação, fitoterapia, atendimento jurídico e outras).

Um reconhecimento está no fato de $67 \%$ dos indicadores terem sido considerados existentes no CSE: controle social, justiça social e eqüidade, desenvolvimento socioeconômico, organização da demanda por ciclo de vida, controle de enfermidades transmissíveis (DST/ AIDS e tuberculose) e não transmissíveis (diabetes e hipertensão), combate à dependência química (exceto tabagismo e não se citou a medicamentosa), contribuição para mudança de estilo de vida, respeito às necessidades do indi- 
víduo e a cultura, comunicação para promoção da saúde e direitos do usuário. Há necessidade de maior investimento nas áreas de organização de protocolos por ciclo de vida, combate ao tabagismo, desenvolvimento ambiental, tecnológico, de pesquisa e capacitação de seus recursos humanos.

Há ainda um grande caminho a percorrer no campo da formação política, tanto de seus profissionais de saúde, que têm uma participação desarticulada no processo de reorientação e nos processos decisórios do CSE, como da população, sejam membros do Conselho Gestor, sejam lideranças comunitárias.

A promoção da saúde, poder, decidir e encaminhar a própria vida está associada a pelo menos três dimensões do empowerment:

- a aproximação dos processos decisórios, contando com a participação efetiva nos fóruns comunitários, conselho distrital, conselho gestor, para determinar a saúde que queremos, que habitação, que ambiente;

- a superação do dualismo indivíduo/coletivo, através de formação de política em que as ações sejam voltadas para o outro, mesmo sem ganhos e até com perdas individuais;

- uma nova relação homem/mulher, em que a mulher possa ter escolhas, determinar sua vi- da independente da vontade e da determinação exclusiva de outro, o que também poderá permitir melhor condição de saúde ao homem, podendo ir ao centro de saúde para promover sua saúde e não apenas quando incapacitados.

A presente pesquisa foi um primeiro ensaio que respaldará reflexões sobre a real dimensão da reorientação do serviço estudado. Sua importância aponta para a necessidade de um aprofundamento, utilizando como estratégia a aproximação entre o serviço, a academia e comunidade, o fortalecimento da intersetorialidade, para ter um aprimoramento mais participativo, estimulando o empowerment.

Construir um modelo de desenvolvimento integral, produtivo e eqüitativo, norteado pelos valores éticos básicos, fundamentado em alianças entre as políticas públicas, a sociedade civil e as organizações dos desfavorecidos, constituído de forma descentralizada, transparente, bem gerenciado e postulando a superação da pobreza e da desigualdade como prioridades fundamentais. Este parece ser o grande desafio que temos pela frente e pretendemos contribuir no aprofundamento, na criação e no monitoramento de indicadores de promoção da saúde baseados em evidências.

\section{Colaboradores}

INC Reis trabalhou na coleta e tabulação de dados, análise dos resultados e levantamento bibliográfico e textos; e MB Vianna na análise de resultados, levantamento bibliográfico e textos

\section{Referências bibliográficas}

Alames, CEBES, PMPA/SMS \& SES/RGS (org.) 2002. Conclusões do I Fórum Internacional em Defesa da Saúde dos Povos. Saúde em Debate 26:123-126.

Bruyne P, Herman J \& Schoutheete M 1982. Dinâmica de Pesquisa em Ciências Sociais. 2a ed. Francisco Alves, Rio de Janeiro.

Buss PM 2000. Promoción de la Salud y la Salud Pública. Fiocruz, Rio de Janeiro.

Canesqui AM (org.) 1995. Dilemas e desafios das ciências sociais na saúde coletiva. Hucitec-Abrasco, São PauloRio de Janeiro. 
Conferência Nacional de Saúde 12 - 2004. Eixos temáticos. Disponível em $<$ http://www.12conferencia.com.br $>$. Acesso em 13 mar.

Fleck MPA 2000. O instrumento de avaliação de qualidade de vida da Organização Mundial da Saúde (WHOQOL-100): características e perspectivas. Ciência \& Saúde Coletiva 5(1):33-38.

Freire P 2000. Pedagogia da autonomia. Paz e Terra, Rio de Janeiro.

Hartz ZA, Bodstein RC, Matida AH (coord.) 2002. Oficina Pesquisa Avaliativa em Promoção da Saúde e Desenvolvimento Comunitário. V Congresso Brasileiro de Epidemiologia, Curitiba.

Health Communication Unit, The 2001. Evaluating health promotion programs. University of Toronto, Canadá.

Lévy-Strauss C 1975. Aula Inaugural, pp. 211-244. In A Zaluar (org.). Desvendando máscaras sociais. Francisco Alves, Rio de Janeiro.

Malo M 2002. Promoção e proteção à saúde 2002. Disponível em $<$ http://www.opas.org.br/projeto $>$. Acesso em 26 jun.

Minayo MCS (org.) 1998. Pesquisa social: teoria, método e criatividade. (Temas Sociais 9). Vozes, Rio de Janeiro.

Minayo MCS, Hartz ZMA \& Buss PM 2000. Qualidade de vida e saúde: um debate necessário. Ciência e Saúde Coletiva 5(1):7-18.

Minayo MCS \& Miranda (org.) 2002. Saúde e ambiente sustentável: estreitando nós. Fiocruz-Abrasco, Rio de Janeiro.
OPAS 2004. Promoção e Atenção à Saúde: reorientação das práticas e serviços de saúde 2004. Disponível em $<$ http://www.opas.org.br>. Acesso em 13 mar.

Penna ACM 2004. A influência do ambiente construído na promoção da saúde: o caso do Centro de Saúde Escola Germano Sinval Faria. Dissertação de mestrado. Faculdade de Arquitetura, Universidade Federal do Rio de Janeiro, Rio de Janeiro.

Reis INC (org.) 2002. Promoção da saúde e reorientação de serviço: a experiência do Centro de Saúde Escola Germano Sinval Faria, pp. 111-157. In L Zancan, R Bodstein \& WB Marcondes (org.). Saúde em Movimento v. 5. Abrasco, Rio de Janeiro.

Reis INC, Buss PM \& Tavares, MFL 2003. Conceito de Promoção da Saúde Segundo a População do Cidade do Rio de Janeiro na Campanha Nacional de Vacinas na Fiocruz, p. 294. In Livro de Resumos do VII Congresso Brasileiro de Saúde Coletiva, Brasília.

Reis INC et al. 2003. Implantação dos padrões de qualidade de atendimento como estratégia de controle Social, p. 581. In Livro de Resumos do VII Congresso Brasileiro de Saúde Coletiva, Brasília.

Stotz EN \& Valla VV 2001. Educação, saúde e cidadania. Vozes, Rio de Janeiro.

Vasconcelos EM 1988. Educação popular nos serviços de saúde. Fiocruz, Rio de Janeiro.

Zancan L, Bodstein R \& Marcondes WB (org.) 2002. Promoção à saúde como caminho para o desenvolvimento local. Saúde em Movimento 5. Abrasco, Rio de Janeiro.

Artigo apresentado em 19/3/2004

Aprovado em 12/7/2004

Versão final apresentada em 21/7/2004 